\title{
Energy exchanges associated with eating and rumination in sheep given grass diets of different physical forms
}

\author{
By P. O. OSUJI*, J. G. GORDON and A. J. F. WEBSTER \\ Rowett Research Institute, Bucksburn, Aberdeen $A B 2{ }_{9} S B$
}

(Received 12 August $1974-$ Accepted 1o October 1974)

\begin{abstract}
I. Energy exchanges and other physiological functions associated with eating and rumination were determined in four experiments. Sheep were given chopped, dried grass (DGC), pelleted, dried grass (DGP) or fresh grass (FGC).

2. In Expt I a preliminary study was made using all three diets. The dry matter (DM) of DGP was eaten significantly faster than that of chopped diets. Sheep salivated most during eating and ruminated longest when given DGC. Rates of contraction for the reticulo-rumen did not differ significantly between diets during idling and rumination, but were significantly faster during eating with DGP. The apparent energy costs of eating were 17 , rog and $176 \mathrm{~kJ} / \mathrm{kg}$ DM eaten for DGP, DGC and FGC respectively, but these probably underestimated the true energy cost.

3. Expt 2 compared DGP and DGC at two levels of intake. The mean energy costs of eating DGP and DGC were 23.5 and $267 \mathrm{~kJ} / \mathrm{kg}$ DM respectively. There was no consistent relationship between the energy cost of eating and the duration of the meal. The proportion of time the sheep spent ruminating DGC was about $23 \%$ but less than I \% for DGP. There was no significant relationship between heat production and the time spent ruminating.

4. In Expt 3 four sheep were offered fresh grass and, later, an equivalent DM intake after the material had been dried. The sheep ate the dried meal significantly faster. The mean energy costs of eating were 208 and $346 \mathrm{~kJ} / \mathrm{kg}$ DM for DGC and FGC respectively. In this experiment the sheep ruminated significantly longer when given FGC, and the energy cost of rumination was $0.11 \mathrm{~kJ} / \mathrm{min}$.

5. Increases in heat production during and after fistula-feeding were only $2-8 \%$ of those obtained during eating, indicating that nearly all the increase in heat production during eating could be attributed to the energy cost of eating per se.

6. The contribution of the energy costs of eating and rumination to the heat increment of feeding and the energy requirement for maintenance of sheep are discussed.
\end{abstract}

The heat production, and thus the energy requirement for maintenance for sheep is usually considered to be the sum of fasting metabolism, the heat increment of feeding, the energy cost of any activity additional to that made during fasting, and the energy cost of maintaining homeothermy. In comfort and confinement, as in a calorimeter, the last two of these factors are taken as zero, the heat increment of feeding is considered to be a function only of the quantity and quality of the food ingested, and the energy expenditure associated with the activity of eating is assumed to be negligible (Agricultural Research Council, 1965). However, there are reliable indications that the energy requirement for maintenance for a sheep kept out of doors but not subject to thermal stress, may exceed that for one kept in a calorimeter by II \% (Blaxter, 1967), $25 \%$ (Langlands, Corbett, McDonald \& Reid, 1963) or even $60-70 \%$ (Young \& Corbett, 1972). It is unlikely that these differences can be attributed entirely to the energy cost of standing and walking at pasture (Clapperton, 1964) and it has been suggested that they could, in part, be due to the increased energy cost of grazing uncut

\footnotetext{
* Present address: Department of Livestock Science, The University of the West Indies, St Augustine, Trinidad, West Indies.
} 
swards (Graham, I 965 ) as the energy cost of eating appears to be more a function of the time spent eating than of the weight of material ingested (Graham, 1965 ; Webster, 1972). Therefore, material which can only be consumed slowly, for example, fresh grass or long hay, would require significantly more energy for eating than readily available concentrated foods such as dried-grass pellets.

The present experiments were designed to study the energy costs associated with eating diets of different physical form, for sheep, and thereby to assess the extent to which these may contribute to their maintenance energy requirements. More detailed descriptions of the experiments have been reported by Osuji (1971, 1973).

\section{EXPERIMENTAL}

Four series of experiments were done.

Expt I. This preliminary experiment was designed to determine the time spent eating and ruminating, rumen movements and parotid saliva flow, heat production and heat loss in sheep given equal amounts of dry matter (DM) $(860 \mathrm{~g} / 24 \mathrm{~h})$ of the following diets: chopped, dried grass (DGC), pelleted, dried grass (DGP) and chopped, fresh grass (FGC). The diets were given as part of a larger experiment involving five diets (Osuji, 1971). The proximate composition of the diets is shown in Table $\mathrm{I}$. The fresh grass was either cut on the morning of the experiment or stored overnight at $4^{\circ}$.

Four adult wether sheep of mixed breeding, weighing about $57 \mathrm{~kg}$ were used. Three of the sheep had been fitted with rumen cannulas before the experiment. The animals were penned individually and had been accustomed to the procedures used, before the experiments began. They were given their daily ration as a single meal at about noon, and allowed access to the food for $\mathrm{I} h$ only. Any food remaining was removed and weighed. Each diet was given for at least 3 weeks before any experimental measurements were made.

Expt 2. In this experiment a more complete comparison was made of the energy exchanges and the activities of eating and rumination for sheep given dried grass either chopped (C) or pelleted (P). The composition of the diets is shown in Table $\mathrm{r}$. Four adult wether sheep having an average initial body-weight of $5 \mathrm{I} \mathrm{kg}$ were used. It was intended to use a $4 \times 4$ Latin-square design but certain changes made during the course of the experiment precluded this (Osuji, I973). Each sheep received each diet for 4 weeks before any measurements were made. Thereafter each animal was kept for $4 \mathrm{~d}$ in a gradient-layer calorimeter (Pullar, 1969) which gave continuous records of heat production and heat loss. Measurements were also made of eating and rumination behaviour. Each diet was offered at two levels: estimated maintenance (M), twice maintenance $(\mathrm{H})$. The sheep were given their ration as a single meal at about noon and given $5 \mathrm{~h}$ to eat it.

Expt 3. Energy exchanges, and eating and rumination behaviour were compared for sheep eating the same grass either fresh or dried. Four adult wether sheep were used (average body-weight $57 \mathrm{~kg}$ ). They were given a single daily meal at 17.00 hours and allowed to eat it. A randomized pair-feeding arrangement was used. The experiment 


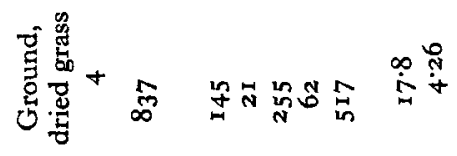

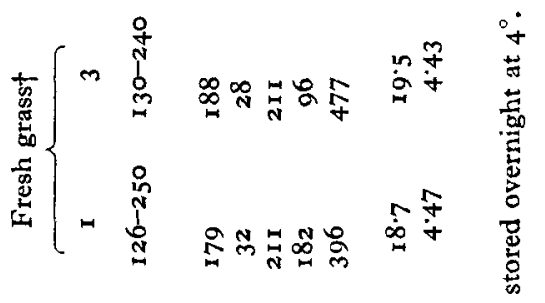

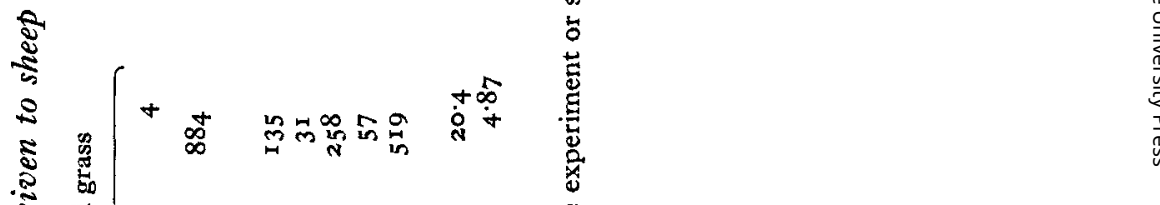


ended at 09.00 hours the next morning. The fresh grass was harvested each morning from a predominantly ryegrass pasture using a flail harvester. The grass was divided into eight $3.5 \mathrm{~kg}$ portions and a sample taken for DM estimation. One portion was given to each of the four sheep and the other four portions were dried in a forced-air oven at $95^{\circ}$. The dried-grass rations given to the sheep throughout the second phase of the experiment corresponded exactly in amounts (DM basis) and origin to the fresh grass that they received during the first part of the experiment. The composition of the grass is shown in Table $\mathrm{I}$.

Expt 4. One sheep with a rumen cannula was used to compare short-term energy exchanges during eating with those during intraruminal feeding. Dried grass was fed either chopped, ground, or ground and pelleted. Since the chemical composition of the dried grass was not markedly altered by physical processing (Table 1 ), only $\mathrm{I}$ week was allowed between successive measurements of energy exchanges.

\section{Physiological measurements}

Energy exchanges. Simultaneous and continuous measurements of heat loss and of heat production from respiratory exchange were made using the gradient-layer calorimeter of Pullar ( $\mathrm{I} 96 \mathrm{~g}$ ), which also operates as an open-circuit respiration chamber. In Expt I measurements were only made between 09.00 and I 7.00 hours and the sheep were restrained by a light webbing harness in a standing position throughout this time, to avoid the marked differences in heat loss between standing and lying that had been obtained previously when using this calorimeter (Brockway, 1965). The animals were fed at noon, but there was some indication that metabolic rate was increased for these animals before feeding probably due both to the anticipation of eating and to the disturbance associated with harnessing. Latterly we discovered that the differences in metabolic rate and heat loss between standing and lying were reduced considerably when the sheep stood on the solid floor of the calorimeter rather than on the raised wire floor of a cage (Gordon, Osuji \& Webster, I972). Therefore in Expts 2 and 3 the sheep were tethered by the neck, allowed to stand and lie at will and measurements of energy exchange were continued for at least $20 \mathrm{~h}$.

In Expt 4, the head of the sheep was enclosed in a ventilated hood which was connected to an open-circuit respiration apparatus.

Heat production was assessed from respiratory exchange using the factors reported by both Brouwer (1965) and McLean (1972). There were no systematic differences between estimates made using the two equations.

Eating and rumination. Movements of the jaw (all experiments) and the reticulorumen (Expt I only) were made using rubber balloons as described by Gordon (1955). Jaw movement records were separated into time spent eating, ruminating and idling. The results were expressed as: the cyclic rate, or time spent ruminating each bolus (total rumination time (s)/no. of boluses regurgitated); the work done in comminuting the food, assessed using Balch's (197I) roughage index (time spent eating + time spent ruminating ( $\min / 24 \mathrm{~h}) / \mathrm{kg}$ DM eaten); a more precise description specifically of rumina- 
tion behaviour was given by a rumination index (percentage of total time spent chewing during rumination $/ \mathrm{kg}$ DM eaten $\times$ roo).

Saliva flow (Expt I). The exit from one parotid salivary duct was cannulated while the sheep was under general anaesthesia, and the cannula was drawn out through the cheek using the method of Ash \& Kay (i959). An extension to this catheter carried saliva to a measuring cylinder placed underneath the metabolism cage. The weighed saliva was returned to the sheep through their rumen fistulas.

General procedures for chemical analysis. For all experiments proximate analysis of food, faeces and urine was done using the procedure of the Association of Official Agricultural Chemists (1965). Nitrogen was estimated for a representative sample using the automated Kjeldahl method of Davidson, Mathieson \& Boyne (1970). The energy content of the food, faeces and urine was estimated using an adiabatic bomb calorimeter (Gallenkamp \& Co. Ltd, London EC2).

Statistical analysis. As the sequence of treatments in Expt I and 2 was not randomized, the results could not be subjected to an analysis of variance, and mean values obtained for each treatment include between-sheep variation. For Expt 3 the treatment sequence was randomized and the results were assessed by analysis of variance.

\section{RESULTS}

Expt I. Measurements for eating and rumination behaviour, saliva production and reticulo-rumen contractions are shown in Table 2. On a DM basis, DGP was eaten conspicuously faster than the other diets $(P<0.00 \mathrm{r})$. Water intake was least for sheep given FGC; those given DGC had a consistently high intake in the $4 \mathrm{~h}$ after the meal. Saliva flow during eating was least for sheep given FGC. Unfortunately saliva flow after eating was not recorded in the first trials when DGC was fed.

The sheep ruminated much longer when given DGC than when given DGP $(P<0.01)$. The ratio, time spent chewing: total time spent ruminating, was also much greater for DGC than for DGP $(P<0.001)$. There was no significant difference between diets in the rates of reticulo-rumen contractions during idling and rumination. However, the contraction intervals were significantly shorter during eating for DGP than for FGC and DGC $(P<0.001)$.

Increases in heat production during eating are shown in Table 3. Heat production before eating was variable and probably increased because the sheep had just entered the calorimeter, were restrained in a standing position and were anticipating their daily meal. Therefore, in this experiment, the increase in heat production due to eating the different diets was obtained by comparing heat production during eating with that obtained $2 \mathrm{~h}$ after the meal, at a time when fermentation and other contributors to the heat increment of feeding were high. The values shown in Table 3 undoubtedly underestimate the true energy cost of eating and are only valid as a method of comparing the different diets.

Differences between diets for total heat production were significant $(P<0.01)$ but differences between sheep were not significant. Differences between diets for the energy cost of eating were significant $(P<0.05)$. Expressed on a $\mathrm{kJ} / \mathrm{min}$ basis, the cost 
Table 2. Expt I. Muscular and secretory activities associated with eating and rumination, for a period of about $8 \mathrm{~h}$ when sheep were given access to chopped, dried grass or pelleted, dried grass or fresh grass for $\mathrm{I} h$

(Mean values with their standard errors, where given, for four sheep)

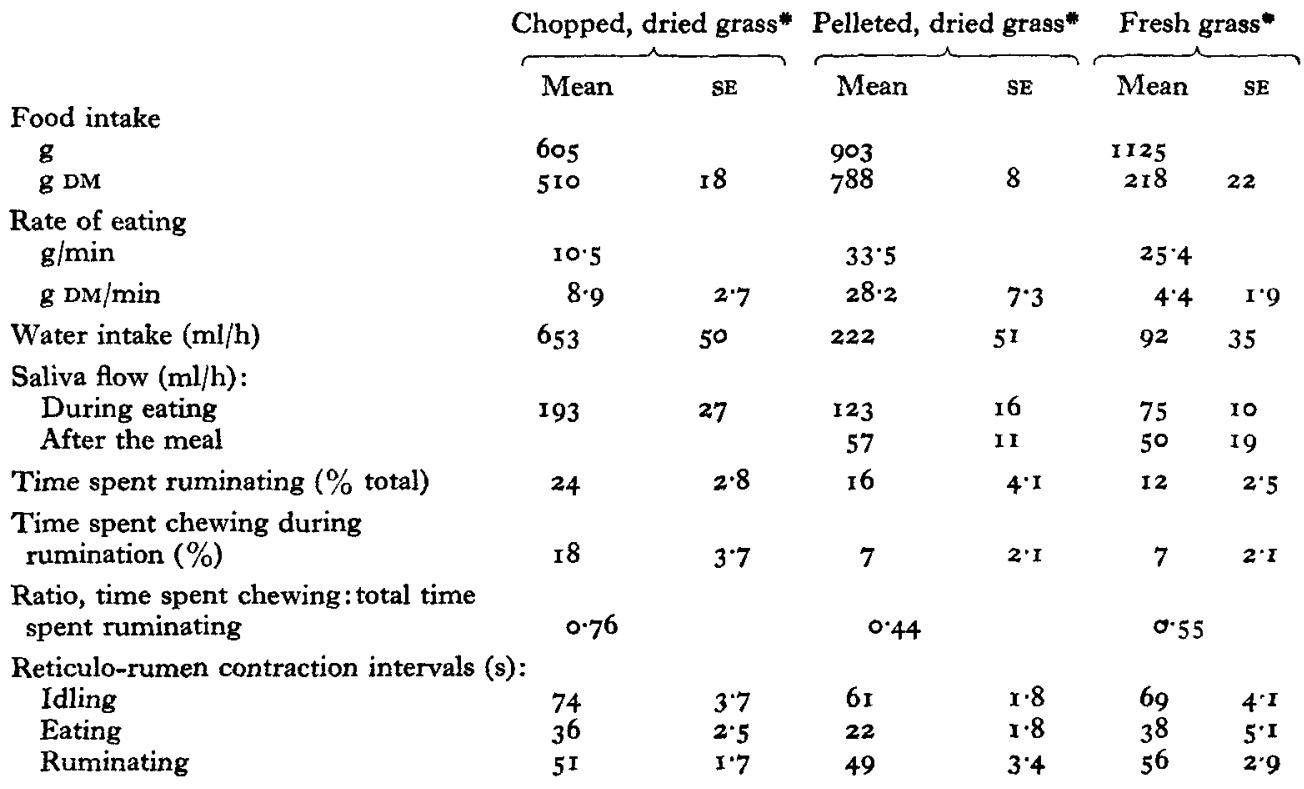

DM, dry matter.

* For details of diets, see Table I and Osuji (r97r).

Table 3. Expt I. The apparent energy cost of eating for four sheep given access to chopped, dried grass or pelleted, dried grass or fresh grass for I $h$ daily

(Mean values with their standard errors, where given)

\begin{tabular}{|c|c|c|c|}
\hline & $\begin{array}{l}\text { Chopped, } \\
\text { dried grass* }\end{array}$ & $\begin{array}{l}\text { Pelleted, } \\
\text { dried grass* }\end{array}$ & Fresh grass* \\
\hline \multicolumn{4}{|l|}{ Food intake } \\
\hline$\stackrel{g}{g}$ DM & $\begin{array}{c}790 \\
671 \pm 16\end{array}$ & $\begin{array}{r}951 \\
828 \pm 9\end{array}$ & $\begin{array}{r}1221 \\
233 \pm 19\end{array}$ \\
\hline Time spent eating (min) & $5^{8} \pm 6$ & $29 \pm 4$ & $49 \pm 6$ \\
\hline $\begin{array}{l}\text { Increase in heat productic } \\
\mathrm{kJ} / \mathrm{h} \\
\mathrm{kcal} / \mathrm{h}\end{array}$ & $\frac{96 \pm 13 \cdot 7}{23}$ & $\frac{25 \pm 3}{6} \cdot 3.9$ & $\begin{array}{l}50 \pm 10.9 \\
12\end{array}$ \\
\hline $\begin{array}{l}\text { Energy cost of eating } \\
\mathrm{kJ}(\mathrm{kcal}) / \mathrm{kg} \text { food } \\
\mathrm{kJ}(\mathrm{kcal}) / \mathrm{kg} \mathrm{DM} \\
\mathrm{kJ}(\mathrm{kcal}) / \mathrm{min}\end{array}$ & $\begin{array}{c}92(22) \\
109(26) \\
I \cdot 270(0.304)\end{array}$ & $\begin{aligned} 12(3) \\
17(4) \\
0.418(0.100)\end{aligned}$ & $\begin{array}{cl}33 & (8) \\
176 & (42) \\
0.837(0.200)\end{array}$ \\
\hline
\end{tabular}

DM, dry matter.

* For details of diets, see Table I and Osuji (I97I). 


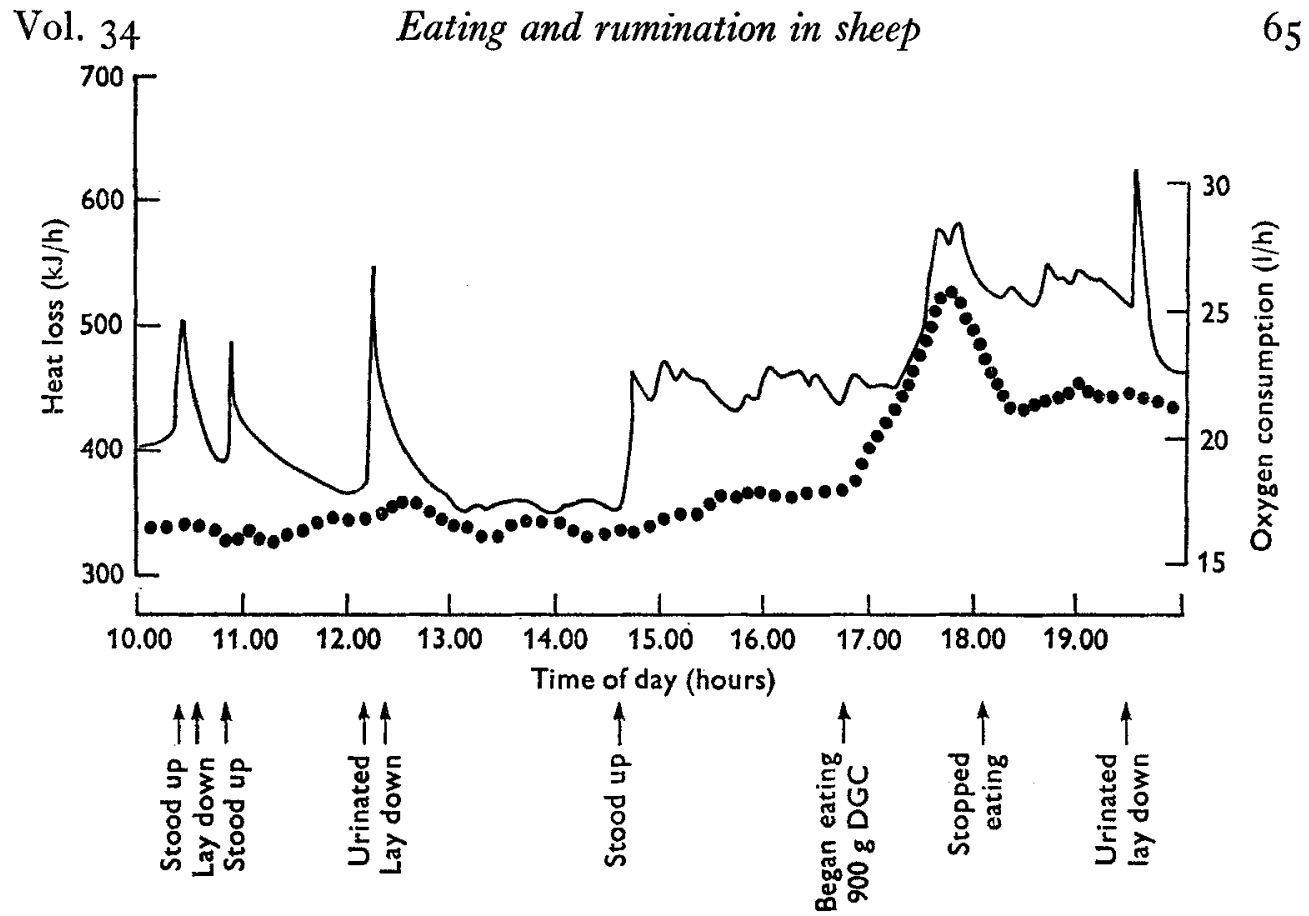

Fig. I. Expt 2. A typical daily record of heat loss (-) and oxygen consumption (C) for a sheep kept for $4 \mathrm{~d}$ in a gradient-layer calorimeter (for details, see Pullar, 1969). DGC, chopped, dried grass; for experimental details, see p. 60.

of eating ranged from 0.418 for DGP to $1 \cdot 27$ for DGC; on a $\mathrm{kJ} / \mathrm{kg}$ DM eaten basis, it ranged from 17 for DGP to 176 for FGC.

Expt 2. Results for behaviour studies are shown in Table 4. DGP was eaten significantly faster than DGC $(P<0.05)$. The duration of the daily meal was surprisingly unrelated to the amount of food eaten. The sheep ruminated much longer when given DGC than when given DGP; for PH (pelleted diet, $2 \times$ maintenance level) the sheep were not found to ruminate. When given DGC, the sheep ruminated for about $90 \mathrm{~min}$ (in a $7 \mathrm{~h}$ period) and the time spent ruminating did not differ significantly between $\mathrm{M}$ and $\mathrm{H}$, the two levels of intake. During rumination, the time actually spent chewing was $75 \%$ for DGC but only $26 \%$ for DGP. Values for the rumination index and the Balch's (I97I) roughage index decreased at the higher level of intake although the decrease was less for the rumination index because the proportion of rumination time that the sheep actually spent chewing was greater for $\mathrm{H}$. The interval between successive regurgitations during rumination did not differ between diets.

Fig. I shows a typical record of heat loss and oxygen consumption for a sheep kept in the gradient-layer calorimeter. Changes in the rate of heat loss were detected almost instantaneously using the gradient-layer principle, but the response to changes in $\mathrm{O}_{2}$ consumption were delayed for about $3 \mathrm{~min}$ and damped due to mixing of chamber gases before analysis. When the sheep stood up or urinated there was a marked but transient increase in heat loss. Very short-term changes in $\mathrm{O}_{2}$ consumption are not detected by the system, but Fig. I shows clearly that $\mathrm{O}_{2}$ consumption did not differ markedly between $\times 1.00$ and 12.30 hours when the sheep was standing and 12.30 and 
Table 4. Expt 2. Eating and rumination behaviour, and the energy cost of eating for four sheep given access to chopped or pelleted, dried grass at two levels (maintenance $(M)$ $2 \times$ maintenance $(H))$ for 5 h daily

(Mean values with their standard errors, where given)

\begin{tabular}{|c|c|c|c|c|}
\hline & \multicolumn{2}{|c|}{ Chopped, dried grass* } & \multicolumn{2}{|c|}{ Pelleted, dried grass* } \\
\hline & M & $\mathrm{H}$ & $\mathrm{M}$ & $\mathrm{H}$ \\
\hline Food intake (g) & 775 & 1080 & $75 \circ$ & 1200 \\
\hline Time spent eating ( $\mathrm{min}$ ) & $77 \pm 16$ & $68 \pm 17$ & $17 \pm 12$ & $16 \pm I I$ \\
\hline Rate of eating (g DM/min) & $10 \pm 14$ & $14 \pm 14$ & $38 \pm 10$ & $58 \pm 10$ \\
\hline $\begin{array}{l}\text { Energy cost of eating } \\
\mathrm{kJ} / \mathrm{min} \\
\mathrm{kcal} / \mathrm{min} \\
\mathrm{kJ}(\mathrm{kcal}) / \mathrm{kg} \mathrm{DM} \\
\mathrm{kJ}(\mathrm{kcal}) / \mathrm{kg} \mathrm{DM} \text { per min }\end{array}$ & $\begin{array}{c}3.05 \pm 0.38 \\
0.73 \\
305(73) \\
3.93(0.94)\end{array}$ & $\begin{array}{c}3.11 \pm 0.3^{8} \\
0.74 \\
230(55) \\
3.39(0.81)\end{array}$ & $\begin{array}{c}0.83 \pm 0.28 \\
0.20 \\
22(5 \cdot 3) \\
1.26(0.30)\end{array}$ & $\begin{array}{c}1 \cdot 48 \pm 0.26 \\
0.35 \\
25(6 \cdot 0) \\
I \cdot 36(0.32)\end{array}$ \\
\hline $\begin{array}{l}\text { Time spent ruminating } \\
(\% \text { total })\end{array}$ & $2 \mathbf{I}$ & 25 & 0.5 & 0.0 \\
\hline $\begin{array}{l}\text { Ratio, time spent chewing: total } \\
\text { time spent ruminating }\end{array}$ & 75 & 75 & 526 & - \\
\hline $\begin{array}{l}\text { Rumination index } \uparrow \\
\text { Balch's (197r) roughage index } \downarrow\end{array}$ & $\begin{array}{r}24 \\
589\end{array}$ & $\begin{array}{r}21 \\
435\end{array}$ & $\begin{array}{c}0.9 \\
45\end{array}$ & - \\
\hline Cyclic rate $\$$ & $6 \mathrm{I}$ & 67 & $4^{8}$ & - \\
\hline $\begin{array}{l}\text { DM, dry matter. } \\
* \text { For details of di } \\
+ \text { Percentage of tir } \\
\ddagger \text { Time spent eatir } \\
\S \text { Total ruminatio }\end{array}$ & $\begin{array}{l}\text { Table I an } \\
\text { ent chewing } \\
\text { me spent run } \\
\text { (s) /no. of b }\end{array}$ & $\begin{array}{l}\text { suji ( } 197 \mathrm{I} \text { ). } \\
\text { ng ruminatio } \\
\text { ting (min/ } 24 \\
\text { ses regurgita }\end{array}$ & $\begin{array}{l}\text { g DM eaten } \times \\
\text { kg DM eaten. }\end{array}$ & \\
\hline
\end{tabular}

14.30 hours when it was lying down. At 14.30 hours the sheep stood up and remained standing and active until it was fed at 16.50 hours. Metabolic heat production and heat loss were both increased at this time for all sheep, the latter usually to a greater extent, suggesting that the sheep were in negative heat balance during this period of about $2 \mathrm{~h}$ in which they were apparently anticipating their daily meal. When the sheep was given $900 \mathrm{~g}$ DGC there was a rapid rise in $\mathrm{O}_{2}$ consumption (Fig. $\mathrm{r}$ ), despite the delayed response of the apparatus, but heat loss did not begin to increase until $30 \mathrm{~min}$ after the beginning of the meal; this too was typical.

Increases in heat production during eating, adjusted for between-animal differences, are shown in Table 4. The increase in heat production during eating $(\mathrm{kJ} / \mathrm{min}, \mathrm{kJ} / \mathrm{kg}$ DM) was significantly greater for the $\mathrm{C}$ diets $(\mathrm{CM}, \mathrm{CH})(P<0.05)$. When expressed on a $\mathrm{kJ} / \mathrm{kg}$ DM per min basis, the difference between the two diets was greater $(P<0.01)$. Mean increases in heat loss during eating $(\mathrm{kJ} / \mathrm{min})$ were $\mathrm{I} .43$ and 0.86 for the $\mathrm{C}(\mathrm{CM}, \mathrm{CH})$ and $\mathrm{P}(\mathrm{PM}, \mathrm{PH})$ diets respectively, significantly less than the increases in heat production $(P<0.05)$. The calculated heat storage during eating was thus $+0.7 \mathrm{I} \mathrm{kJ} / \mathrm{min}$ for DGC and $+0.43 \mathrm{~kJ} / \mathrm{min}$ for DGP. A positive heat balance of $0.7 \mathrm{~kJ} / \mathrm{min}$, sustained for $\mathrm{I} \mathrm{h}$, would result in an average body temperature increase of about $0 \cdot 22^{\circ}$.

There was no significant relationship between total heat production and the total 
Table 5. Expt 3. Eating and rumination behaviour, and the energy cost of eating for four sheep each given access to $3.5 \mathrm{~kg}$ portions of freshly harvested grass and of the same grass after it had been dried at $95^{\circ}$; all portions had the same dry matter (DM) content

\begin{tabular}{|c|c|c|c|}
\hline & Fresh grass* & Dried grass* & $\begin{array}{l}\text { SE of difference } \\
\text { between mean values }\end{array}$ \\
\hline \multicolumn{4}{|l|}{ Food intake } \\
\hline g & 3423 & 592 & - \\
\hline g DM & 595 & 541 & - \\
\hline Time spent eating (min) & I I 4 & 86 & $2 \cdot 52$ \\
\hline Rate of eating (g DM/min) & $5 \cdot 2$ & $6 \cdot 3$ & 0.29 \\
\hline $\begin{array}{l}\text { Increase in heat production durin } \\
\mathrm{kJ}(\mathrm{kcal}) / \mathrm{min} \\
\mathrm{kJ}(\mathrm{kcal} / \mathrm{kg} \mathrm{DM} \\
\mathrm{kJ}(\mathrm{kcal}) / \mathrm{kg} \mathrm{DM} \text { per } \min \end{array}$ & $\begin{array}{l}1 \cdot 80(0.43) \\
346(82 \cdot 7) \\
3.03(0.72)\end{array}$ & $\begin{array}{l}I \cdot 3 I \quad(0.31) \\
208(49 \cdot 7) \\
2 \cdot 42(0.58)\end{array}$ & $\begin{array}{l}0.59 \\
- \\
-\end{array}$ \\
\hline Time spent ruminating ( $\%$ total) & 23 & I I & $I \cdot 70$ \\
\hline $\begin{array}{l}\text { Ratio, time spent chewing: total ti } \\
\text { spent ruminating }\end{array}$ & 0.70 & 0.72 & 0.03 \\
\hline Rumination index $\uparrow$ & 27 & I4 & $1 \cdot 50$ \\
\hline Balch's (I97I) roughage indext & 710 & $42 I$ & $15 \cdot 3$ \\
\hline Cyclic rate $\$$ & 47 & $5 I$ & 0.95 \\
\hline
\end{tabular}

time spent ruminating the DGC diets. This would suggest that the energy cost of rumination is very low, certainly lower than the value of about $0.8 \mathrm{~kJ} / \mathrm{min}$ suggested by Graham ( 1965 ).

Expt 3. Table 5 shows the results for behaviour studies, and the energy cost of eating for four sheep given access to comparable amounts of DM from the same grass in either the fresh or dried form. The amounts of DM eaten in the fresh and dried forms differed slightly but not significantly. The sheep did, however, eat the dried-grass meal significantly faster $(P<0.05)$. The increase in heat production during eating $(\mathrm{kJ} / \mathrm{min})$ was about $37 \%$ higher for fresh grass than for dried grass. Expressed on a $\mathrm{kJ} / \mathrm{kg} \mathrm{DM}$ eaten basis, the increase during the fresh-grass meal was about $66 \%$ greater than during the dried-grass meal $(P<0.05)$. The energy cost of eating dried grass for this experiment was however rather lower than that obtained in the previous trial (Table 6) although the difference was not significant.

The sheep spent more than twice as long ruminating when given fresh grass than when given dried grass $(P<0.001)$. The ratio, time spent chewing: total time spent ruminating, was the same, therefore the rumination index and Balch's (197r) roughage index gave the same indication of the work done by the sheep in comminuting the food. The cyclic rate was significantly more rapid with fresh grass than with dried grass $(P<0.05)$. In this experiment, where measurements of jaw movements were continued for about $22 \mathrm{~h}$, there was a significant relationship between time spent ruminating and heat production for sheep eating fresh grass, which indicated that the energy 


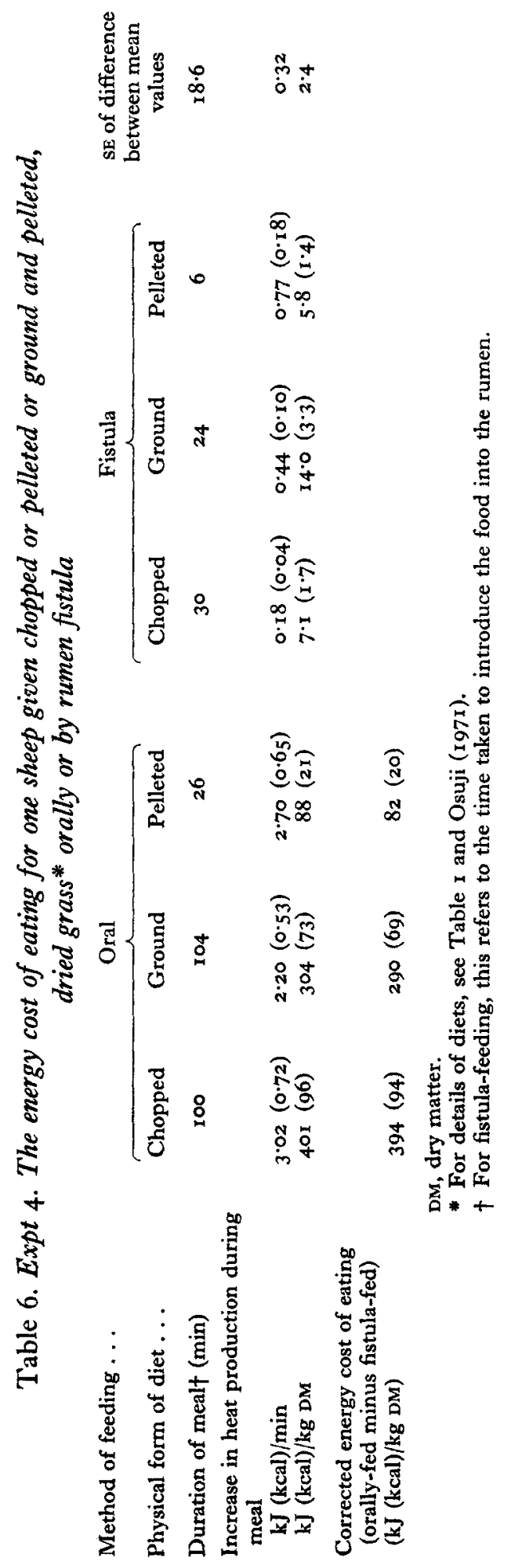


Table 7. Contribution of the energy costs of eating and rumination to the heat increment of feeding for four sheep given access to grass diets of different physical forms, based on the results of Expts 2 and 3

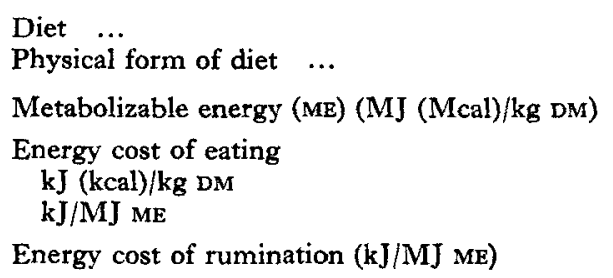

\begin{tabular}{|c|c|c|}
\hline \multicolumn{2}{|c|}{ Dried grass } & Fresh grass \\
\hline Chopped & Pelleted & Chopped \\
\hline $11 \cdot 5(2 \cdot 74)$ & $9.8(2 \cdot 3)$ & $11 \cdot 9(2 \cdot 8)$ \\
\hline $240(57)$ & $24(5 \cdot 7)$ & $390(93)$ \\
\hline $2 I$ & $2 \cdot 5$ & 33 \\
\hline $2 \cdot 3$ & 0.1 & $3 \cdot 6$ \\
\hline
\end{tabular}

DM, dry matter.

cost of ruminating fresh grass was $0.1 \mathrm{I}$ (SE 0.3 ) $\mathrm{kJ} / \mathrm{min}$. Again no significant relationship between time spent ruminating and heat production was obtained for sheep eating dried grass.

Expt 4. Table 6 shows the increase in heat production obtained for one sheep when it ate normally (oral-feeding) and when the same amount of food was introduced into the rumen through a fistula. The increases in heat production during and after fistulafeeding were only $2-8 \%$ of those obtained during oral-feeding, which indicated that nearly all the increase in heat production during eating can be attributed to the energy cost of eating per se rather than to the energy-demanding processes associated with digestion and metabolism of the food eaten.

\section{DISCUSSION}

The best estimates for the energy cost of eating and ruminating FGC, DGC and DGP are given in Table 7. These are based on the results of Expts 2 and 3. The energy cost of rumination is based on the rumination index for each diet and the assumption that the energy cost of rumination/min is independent of the nature of the diet, and about $0.1 \mathrm{I} \mathrm{kJ} / \mathrm{min}$ spent chewing.

The value, $240 \mathrm{~kJ} / \mathrm{kg} \mathrm{DM}$, for the energy cost of eating DGC compares well with an average value, about $300 \mathrm{~kJ} / \mathrm{kg} \mathrm{DM}$, for the energy cost of eating hay, reported by Webster (1972) in a review of values obtained before that date. It is reasonable to assume that the energy cost of eating hay would be somewhat intermediate between DGC and FGC, as shown in Table 7 .

The results also suggested the rather obvious point that the total energy cost of eating a meal is related to the time taken to eat it. This relationship was less exact than had been suggested by Graham (1965) and Webster (1972), but as a first approximation the results of Expts 2 and 3 indicated that the energy cost of eating was about $2.2 \mathrm{~kJ}(0.54 \mathrm{kcal}) / \mathrm{kg}$ body-weight per $\mathrm{h}$ spent eating, which is in exact agreement with the estimates of Webster ( 1972 ). However, Tables 4 and 5 show that there were marked differences, both between and within diets, for the energy cost of eating expressed on a $\mathrm{kJ} / \mathrm{min}$ basis. The energy cost of eating, for sheep, cannot therefore be predicted accurately without taking into account the physical form of the diet. The corollary to 
this is that the physical form of the diet must affect the increase in heat production associated with eating the diet, and thus the efficiency with which metabolizable energy (ME) is used for maintenance and for production. Wainman, Blaxter \& Smith (1972) showed that the efficiency of utilization of dried grass for maintenance was about $73 \%$ for chopped material but about $78 \%$ for pelleted material. Results shown in Table 7 suggested that about half this difference could be attributed to the difference in the amount of energy required to eat and to ruminate the two materials. Ekern, Blaxter \& Sawers (1965) found that when sheep were offered the same grass either fresh or dried, the increases in heat production (eating compared with fasting metabolism) were $40 \mathrm{I}$ and $345 \mathrm{~kJ} / \mathrm{MJ}$ respectively, a difference of $5^{6} \mathrm{~kJ} / \mathrm{MJ}$. The difference between the energy cost of eating and ruminating fresh and dried grass in the present experiments was only $I 3 \mathrm{~kJ} / \mathrm{MJ}$, which suggested that only about onequarter of the difference between the efficiency of utilization of fresh and dried grass could be attributed to the physical form of the diet.

The present experiments do not show whether the energy cost of grazing at pasture (additional to the energy cost of walking while grazing) is greater, in terms of $\mathrm{kJ} / \mathrm{MJ}$ ME consumed, than when FGC is eaten from a manger. Graham (1965) suggested it was at least twice as great; in his experiments the increase in the rate of heat production/min, for sheep, was the same whether they were eating FGC or grazing an uncut sward, although they were able to eat FGC more than twice as fast. If we assume that the energy cost of grazing is twice that of eating cut grass, this would result in an increase of about $10 \%$ in the maintenance requirements of sheep at pasture compared with that of an animal kept in a calorimeter. Blaxter (1967) assumed that the energy cost of walking at pasture would add about i I \% to the maintenance requirement of sheep at pasture. If an additional $10 \%$ is added for the energy cost of grazing per se, then the difference between the maintenance energy requirement for confined sheep and that for sheep at pasture is about $25 \%$, the value obtained by Langlands et al. (r963), although it is still much less than the estimate of $60-70 \%$ made by Young $\&$ Corbett (1972) under Australian conditions, where the density of the grass was rather low.

The energy cost of ruminating would appear from the results of our work to be very small indeed, considerably less than previous estimates of Graham (I965) and Ustjanzew (I9II). These results support the conclusion of Webster (1972) that the energy cost of eating is too great to be simply the result of the cost of chewing and salivating, as these activities are common to eating and rumination. Some of the factors that may contribute to the energy cost of eating have been discussed by Webster (1972). The most obvious difference between eating and rumination is that during eating the sheep is standing and alert whereas during rumination it is usually lying down and at rest. Bell (1958, 1960) showed that for the goat the electroencephalogram obtained during rumination is indistinguishable from that obtained during somnolence. The present results therefore support the suggestion of Gordon (I968) that one of the many beneficial aspects of rumination to the sheep is that it enables it to harvest food relatively fast and then comminute it literally at its leisure, and at negligible cost in terms of energy. 


\section{REFERENCES}

Agricuitural Research Council (1965). Nutrient Requirements of Farm Livestock No. 2, Ruminants. London: Agricultural Research Council.

Ash, R. W. \& Kay, R. N. B. (1959). F. Physiol., Lond. I49, 43.

Association of Official Agricultural Chemists (1965). Official Methods of Analysis, 1oth ed. Washington, DC: Association of Official Agricultural Chemists.

Balch, C. C. (197I). Br. F. Nutr. 26, 383 .

Bell, F. R. (1958). F. Physiol., Lond. 143, 46P.

Bell, F. R. (1960). Anim. Behav. 8, 39.

Blaxter, K. L. (1967). The Energy Metabolism of Ruminants, and ed. London: Hutchinson Scientific and Technical.

Brockway, J. M. (1965). Publs Eur. Ass. Anim. Prod. no. I 1, p. 395.

Brouwer, E. (1965). Publs Eur. Ass. Anim. Prod. no. I I, p. 44 I.

Clapperton, J. L. (1964). Br. F. Nutr. 18, 47.

Davidson, J., Mathieson, J. \& Boyne, A. W. (1970). Analyst, Lond. 95, I81.

Ekern, A., Blaxter, K. L. \& Sawers, D. (1965). Br.F. Nutr. 19, $4^{\text {r } 7 . ~}$

Gordon, J. G. (1955). Rumination in the sheep. PhD Thesis, University of Aberdeen.

Gordon, J. G. (1968). Wld Rev. Nutr. Diet. 9, 25 I.

Gordon, J. G., Osuji, P. O. \& Webster, A. J. F. (1972). F. Physiol., Lond. 227, 5 P.

Graham, N. McC. (1965). Publs Eur. Ass. Anim. Prod. no. I1, p. 23 I.

Langlands, J. P., Corbett, J. L., McDonald, I. \& Reid, G. W. (Ig63). Anim. Prod. 5, I.

McLean, J. A. (1972). Br. \%. Nutr. 27, 597.

Osuji, P. O. (1971). Energy exchanges and related phenomena in sheep eating rations of different physical forms. MSc Thesis, University of Aberdeen.

Osuji, P. O. (1973). Ruminant energy metabolism: an analysis of the heat increment of feeding in sheep. PhD Thesis, University of Aberdeen.

Pullar, J. D. (1969). In International Encyclopaedia of Food and Nutrition, vol. I7, p. 417 [D. P. Cuthbertson, editor]. London: Pergamon Press.

Ustjanzew, W. (1911). Biochem. Z. 37, 475 .

Wainman, F. W., Blaxter, K. L. \& Smith, J. S. (1972). F. agric. Sci., Camb. 78, 44 I.

Webster, A. J. F. (1972). Proc. int. Symp. Envir. Physiol. p. 42.

Young, B. A. \& Corbett, J. L. (1972). Aust. F. agric. Res. 23, 57. 